\title{
Diastolic myofilament dysfunction in the failing human heart
}

\author{
Jolanda van der Velden
}

Received: 17 March 2011 /Revised: 23 March 2011 /Accepted: 24 March 2011 /Published online: 13 April 2011

(C) The Author(s) 2011. This article is published with open access at Springerlink.com

\begin{abstract}
In recent years, it has become evident that heart failure is not solely due to reduced contractile performance of the heart muscle as impaired relaxation is evident in almost all heart failure patients. In more than half of all heart failure patients, diastolic dysfunction is the major cardiac deficit. These heart failure patients have normal (or preserved) left ventricular ejection fraction, but impaired diastolic function evident from increased left ventricular end-diastolic pressure. Perturbations at the cellular level which cause impaired relaxation of the heart muscle involve changes in $\mathrm{Ca}^{2+}$-handling proteins, extracellular matrix components, and myofilament properties. The present review discusses the deficits in myofilament function observed in human heart failure and the most likely underlying causal protein changes. Moreover, the consequences of impaired myofilament function for in vivo diastolic dysfunction are discussed taking into account the reported changes in $\mathrm{Ca}^{2+}$ handling.
\end{abstract}

Keywords Diastole $\cdot$ Myocardial contractility $\cdot$ Muscle stiffness $\cdot$ Myofilament $\cdot$ Phosphorylation $\cdot$ Heart

\section{Systolic and diastolic function of the heart: role of the myofilaments}

Every heart beat, the ventricles eject blood into the small and large circulation to provide organs with sufficient oxygen. Cardiac output depends on the amount of blood

J. van der Velden $(\bowtie)$

Laboratory for Physiology, Institute for Cardiovascular Research

(ICaR-VU), VU University Medical Center,

van der Boechorststraat 7,

1081 BT, Amsterdam, the Netherlands

e-mail: j.vandervelden@vumc.nl ejected per heart beat (i.e., stroke volume) and heart rate. Although myocardial muscle contraction is indispensible for proper cardiac output during the systolic (activation) phase of the cardiac cycle, filling of the ventricles during the diastolic (relaxation) phase heavily depends on proper cardiac muscle relaxation. The latter is even more important during increased cardiac stress as occurs during exercise. To match cardiac output to increased demands of the body, heart rate is increased by enhanced sympathetic drive. The magnitude of contraction is increased by increased $\mathrm{Ca}^{2+}$ induced $\mathrm{Ca}^{2+}$-release from the sarcoplasmic reticulum (SR) within the heart muscle cells. To match the increase in heart rate, a faster relaxation of the heart muscle is required which is achieved by increased re-uptake of $\mathrm{Ca}^{2+}$ into the $\mathrm{SR}$ and desensitization of the myofilaments to $\mathrm{Ca}^{2+}[6,56]$.

Upon depolarization of the heart muscle cells, L-type $\mathrm{Ca}^{2+}$-channels are opened, which causes $\mathrm{Ca}^{2+}$ entry into the cytosol and triggers $\mathrm{Ca}^{2+}$ release from the $\mathrm{SR}$ via the ryanodine receptors (RyR2; so-called $\mathrm{Ca}^{2+}$-induced $\mathrm{Ca}^{2+}$ release). Subsequently, $\mathrm{Ca}^{2+}$ binds to troponin $\mathrm{C}$ and initiates myofilament contraction via interactions between the thick filament myosin heads and the thin filament component actin. Relaxation of the heart muscle cells occurs upon detachment of $\mathrm{Ca}^{2+}$ from the troponin complex and subsequent re-uptake of $\mathrm{Ca}^{2+}$ into the $\mathrm{SR}$ via the SR $\mathrm{Ca}^{2+}$-ATPase (SERCA2), which activity depends on the phosphorylation status of phospholamban (i.e., unphosphorylated phospholamban blocks SERCA2 activity). SERCA2 is responsible for re-uptake of $\sim 70 \%$ of the $\mathrm{Ca}^{2+}$ involved in the $\mathrm{Ca}^{2+}$ transient and approximately $30 \%$ of the cytosolic $\mathrm{Ca}^{2+}$ is removed out of the cell via the $\mathrm{Na}^{+}-$ $\mathrm{Ca}^{2+}$ exchanger (NCX) [6, 7]. Changes in cellular $\mathrm{Ca}^{2+}$ cycling and myofilament properties are under the tight control of kinases and phosphatases within the heart muscle cells, which respectively phosphorylate and dephosphory- 
late cellular target proteins that regulate contraction and relaxation $[29,51]$. Upon increased sympathetic activation, $\beta_{1}$-adrenergic receptors are activated which initiates protein kinase A (PKA)-mediated phosphorylation of proteins involved in $\mathrm{Ca}^{2+}$ handling (RyR2, phospholamban) and of the myofilament target proteins troponin I (cTnI), myosin binding protein $\mathrm{C}$ (cMyBP-C), and titin [6, 28, 40, 56, 75]. The predominant role of the myofilaments during increased $\beta_{1}$-adrenergic receptor stimulation is enhancement of relaxation, which is caused by desensitization of the myofilaments to $\mathrm{Ca}^{2+}$ (Fig. 1a) and faster kinetics of

A.

$\beta$-adrenergic receptor-mediated myofilament $\mathrm{Ca}^{2+}$-desensitization

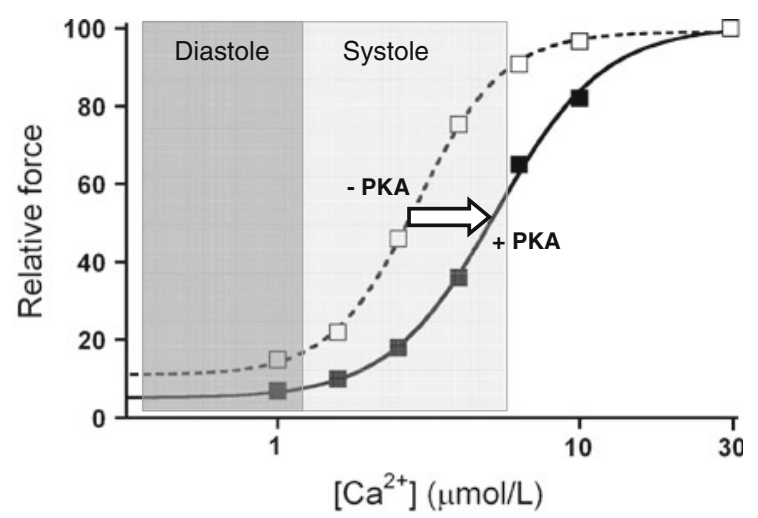

B. Length-dependent activation of myofilaments

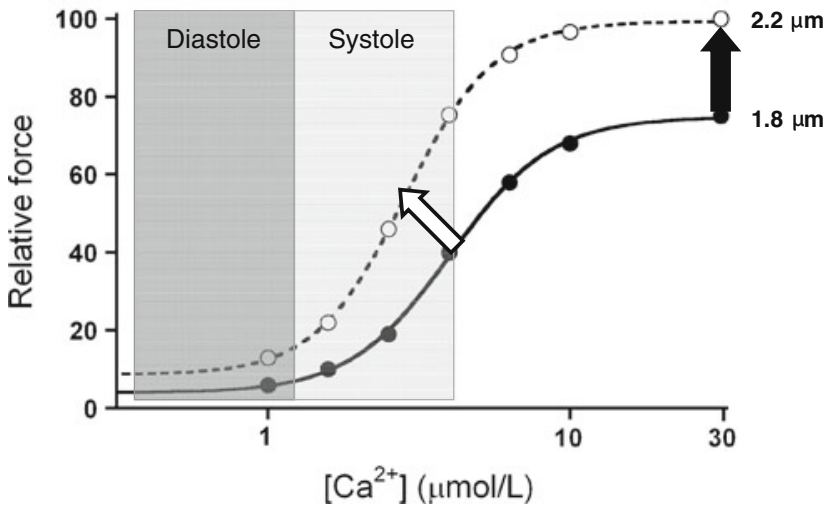

Fig. 1 Myofilament responses to increased sympathetic activation and increased left ventricular filling during diastole (Frank-Starling mechanism). a Activation of protein kinase A (PKA) upon $\beta$ adrenergic receptor stimulation increases phosphorylation of myofilament proteins (troponin $\mathrm{I}$, myosin binding protein $\mathrm{C}$ and titin) and thereby reduces myofilament $\mathrm{Ca}^{2+}$-sensitivity (indicated by the white arrow), enhances cross-bridge kinetics and lowers passive stiffness. The PKA-mediated changes in myofilament properties contribute to enhanced muscle relaxation, which is required for proper filling of the heart during diastole. b An increase in left ventricular filling (increased end-diastolic left ventricular volume) increases the maximal force-generating capacity (black arrow) and myofilament $\mathrm{Ca}^{2+}$ sensitivity (white arrow) and underlies increased cardiac output during the subsequent systolic phase cross-bridge cycling $[17,77]$. The PKA-mediated phosphorylation of $\mathrm{cTnI}$ is thought to be the major contributor to myofilament $\mathrm{Ca}^{2+}$-desensitization [56]. More recent studies have indicated a modulating role for $\mathrm{CMyBP}-\mathrm{C}$ in the PKAmediated reduction of myofilament $\mathrm{Ca}^{2+}$-sensitivity $[16,17$, 37], although the major effect exerted by phosphorylated cMyBP-C seems to be enhancement of the rate of contraction and relaxation $[39,44,58,59]$. The third protein phosphorylated upon $\beta_{1}$-adrenergic receptor activation is the giant protein titin [75], which, upon PKAmediated phosphorylation, reduces passive stiffness of cardiac muscle cells $[11,40,75]$. Overall, the PKAmediated enhancement of myofilament relaxation is critical to maintain proper cardiac performance at increased heart rates associated with $\beta$-adrenergic stimulation.

Apart from phosphorylation-induced changes in myofilament function, a change in sarcomere length upon increased filling of the ventricles during diastole increases the maximal force-generating capacity and the $\mathrm{Ca}^{2+}$ sensitivity of the myofilaments (Fig. 1b). This lengthdependent activation is called the Frank-Starling mechanism of the heart and underlies increased cardiac output at increased left ventricular (LV) end-diastolic volumes. The exact mechanisms underlying the increased forcegenerating capacity of the myofilaments at higher sarcomere lengths are still controversial and have been extensively discussed in previous reviews $[33,36]$.

Lastly, changes in heart rate adjust myofilament properties to cardiac pump performance [2, 42, 43, 69]. Under physiological conditions, an increase in cardiac stimulation frequency results in enhanced systolic function (so-called positive force-frequency relation), which has been attributed to an increased $\mathrm{Ca}^{2+}$ influx into the cardiomyocytes. The increase in $\mathrm{Ca}^{2+}$ influx increases $\mathrm{SR} \mathrm{Ca}{ }^{2+}$ content and promotes the $\mathrm{Ca}^{2+}$-induced $\mathrm{Ca}^{2+}$-release. Varian and Janssen [69] observed a decrease in myofilament $\mathrm{Ca}^{2+}$-sensitivity with increased frequency in the healthy myocardium and suggested that, similar to $\beta$ adrenergic PKA-mediated $\mathrm{Ca}^{2+}$-desensitization, the frequency-induced myofilament $\mathrm{Ca}^{2+}$-desensitization accelerates relaxation of the heart muscle. The frequency-mediated alteration in myofilament $\mathrm{Ca}^{2+}$-sensitivity most likely involves changes in protein phosphorylation caused by $\mathrm{Ca}^{2+}$-activated kinases $[42,61,70]$.

\section{Systolic and diastolic heart failure}

The amount of blood ejected as a fraction of total blood in the ventricles at the end of the diastolic phase is called the ejection fraction. In clinical practice, LV ejection fraction (LVEF) is used as a measure to define systolic cardiac performance. A patient with a LV ejection fraction $<45 \%$ 
has heart failure with reduced ejection fraction (HFREF) or systolic heart failure. Over the last two decades, it became evident that more than $50 \%$ of all heart failure patients suffer of heart failure with normal (or preserved) ejection fraction (HFNEF) [53]. Compared to HFREF patients, these so-called HFNEF patients have a higher mortality and morbidity $[1,8]$. The main perturbation in HFNEF patients is diastolic dysfunction. Moreover, frequently, patients with systolic dysfunction also show impaired diastolic function. The epidemiologic evidence that diastolic rather that systolic dysfunction is a major cause of cardiac failure in Western society has triggered scientists to investigate the underlying mechanisms of diastolic dysfunction in humans.

Perturbations at the cellular level which are thought to underlie diastolic dysfunction in human heart failure are: impaired $\mathrm{Ca}^{2+}$-handling [7], extracellular matrix modifications [11, 63], and myofilament dysfunction [29, 30, 67, 73]. In heart failure, the decline in the cytosolic $\mathrm{Ca}^{2+}$ transient is slowed, which is most likely caused by reduced re-uptake of $\mathrm{Ca}^{2+}$ into the SR due to reduced SERCA2 expression and reduced PKA-mediated phosphorylation of phospholamban. The reduced $\mathrm{Ca}^{2+}$-transient decline contributes to diastolic dysfunction and hampers ventricular filling during the relaxation phase of the heart. The reduced $\mathrm{Ca}^{2+}$ re-uptake also lowers SR $\mathrm{Ca}^{2+}$ content and thereby reduces the amount of $\mathrm{Ca}^{2+}$ available for the subsequent contraction. Thus, perturbations in $\mathrm{Ca}^{2+}$ handling contribute to both systolic and diastolic dysfunction of the heart. Cardiac dysfunction has been ascribed to alterations in the extracellular matrix. Stiffness of the extracellular matrix is largely determined by collagen through regulation of its total amount, the relative abundance of collagen type I and the degree of collagen cross-linking. Excessive collagen type I deposition results from an imbalance between an exaggerated synthesis and a depressed degradation. Comparison of myocardial structure of LV endomyocardial catheter biopsies from HFNEF and HFREF patients showed similar increases in collagen volume fraction in both groups (respectively, $12.2 \pm 1.4 \%$ and $14.4 \pm 1.5 \%$ ) compared to normal values $(5.4 \pm 2.2 \%)[63]$. In the HFREF group, collagen deposition was significantly enhanced by diabetes mellitus and associated with increased deposition of AGEs (advanced glycation end products) [64]. AGEs result from long-standing hyperglycemia and augment passive stiffness via cross-linking and enhanced collagen formation. Recently, Westermann et al. [72] provided evidence that enhanced deposition and remodelling of the extracellular matrix in HFNEF patients may involve myocardial inflammation. In addition to collagen deposition, intrinsic cardiomyocyte stiffness contributes to LV diastolic dysfunction evident from the high myofilament passive force observed in patients with HFNEF and HFREF [63].

\section{Diastolic heart failure: role of the myofilaments}

The first studies on myofilament function in membranepermeabilized single cell preparations were already performed more than 30 years ago $[22,26]$. Myofilament function is commonly measured in Triton-permeabilized cardiac muscle preparations, which allows investigation of myofilament properties without interference of extracellular matrix components and under well-controlled conditions (e.g., fixed sarcomere length and calcium concentration) [65]. Nowadays, single cells can be isolated from small needle biopsies, which are obtained during cardiac surgery or cardiac catheterization $[11,18]$. The major limitation of the method may be the small size of the human cardiac tissue samples available for research, as throughout the heart, regional and transmural differences may exist in myofilament properties. Heterogeneity in myofilament function and protein phosphorylation may be larger in cardiac disease as the disease trigger may be localized to a certain area of the heart. Transmural differences in myofilament properties have been reported in rodent studies $[15,21]$. To assess regional differences in myofilament properties in the human heart, LV subepiand subendocardial biopsies were obtained during valve replacement surgery from patients with mitral valve or aortic valve stenosis or insufficiency [66]. In the latter study, we did not find evidence for regional differences in myofilament function and protein composition within the human ventricle. In addition, recent analysis of variability of the phosphorylation of the PKA target proteins cTnI and cMyBP-C showed that the intra-patient variability in protein phosphorylation was comparable between donor and cardiomyopathy samples [62]. Thus, our data indicate that within the precision of the measurements small, biopsy-sized cardiac human tissue samples are representative for the region of the free LV wall from which they are obtained.

The initial studies in humans were done in samples obtained during heart transplantation surgery from endstage failing patients with idiopathic (IDCM) or ischemic (ISHD) cardiac disease $[67,73]$. A comparison was made with cells isolated from non-failing donor hearts. Myofilament $\mathrm{Ca}^{2+}$-sensitivity was increased in end-stage failing compared to donor hearts as illustrated in Fig. 2a. The higher sensitivity for $\mathrm{Ca}^{2+}$ in end-stage failing hearts may exert a beneficial effect on systolic cardiac performance, but it may limit relaxation during diastole. Diastolic function may be further impaired by the combined changes in myofilament properties and perturbations in $\mathrm{Ca}^{2+}$ handling as discussed above. The blunted decline in $\mathrm{Ca}^{2+}$-transient decay in failing myocardium will increase diastolic $\mathrm{Ca}^{2+}$ levels and exaggerate diastolic dysfunction as shown in Fig. $2 b$. 
A. Increased myofilament $\mathrm{Ca}^{2+}$-sensitivity in end-stage heart failure

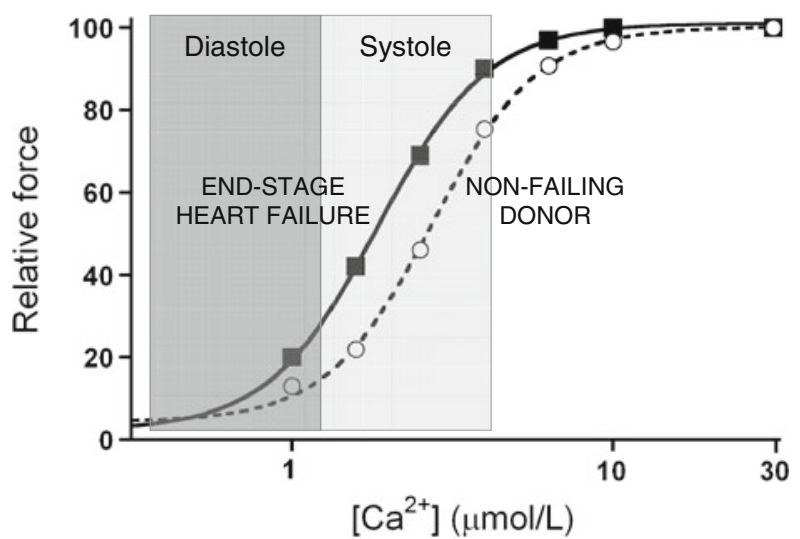

B.

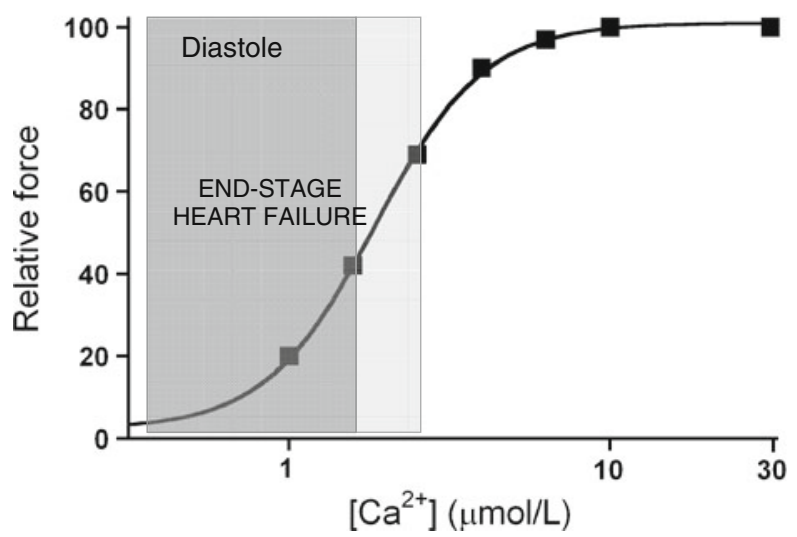

Fig. 2 a Force measurements in single Triton-permeabilized cardiomyocytes from end-stage failing patients with ischemic and idiopathic cardiomyopathy showed increased myofilament $\mathrm{Ca}^{2+}$-sensitivity compared to non-failing donor hearts [67]. Translation of the altered responsiveness to $\mathrm{Ca}^{2+}$ to cardiac pump function suggests that the force-generating capacity of myofilaments will be higher at systolic $\left[\mathrm{Ca}^{2+}\right]$ and improves cardiac output, while the enhanced myofilament $\mathrm{Ca}^{2+}$-sensitivity may impair relaxation of the heart muscle during diastole. b Taking into account the reported changes in the $\mathrm{Ca}^{2+}$ transient in human heart failure (i.e. reduced systolic peak $\mathrm{Ca}^{2+}$ and slowed diastolic $\mathrm{Ca}^{2+}$ decline [7]) would further worsen diastolic function. The combination of enhanced myofilament $\mathrm{Ca}^{2+}$-sensitivity and increased diastolic $\mathrm{Ca}^{2+}$ levels is illustrated in $\mathbf{b}$

The enhanced myofilament $\mathrm{Ca}^{2+}$-sensitivity has been ascribed to defects in the $\beta$-adrenergic receptor pathway as reduced phosphorylation of the PKA target proteins, cTnI and $\mathrm{cMyBP}-\mathrm{C}$, has been reported in end-stage failing compared to non-failing donor myocardium $[9,20,25$, $48,67]$. In further support for defective $\beta$-adrenergic signaling was the observation that myofilament $\mathrm{Ca}^{2+}$. sensitivity was normalized to donor values after treatment of cells with exogenous PKA [67]. Enhanced myofilament $\mathrm{Ca}^{2+}$-sensitivity and correction to control values with PKA treatment have been observed in different animal models as well (e.g., post myocardial infarction or pressure overload) $[23,30,68]$. However, in all animal models, it has been difficult to find proof for reduced PKA-mediated phosphorylation of cTnI and cMyBP-C [30]. Only recently, we have observed a blunted cTnI phosphorylation at the PKA sites (Serines 23/24) upon dobutamine infusion in postinfarction compared to sham pigs [10]. In contrast, the dobutamine-induced phosphorylation of cMyBP-C at Ser282 (one of the PKA sites) was preserved in postinfarction hearts, and coincided with increased autophosphorylation of the cytosolic $\mathrm{Ca}^{2+}$-dependent calmodulin kinase II (CaMKII- $\delta$ C) [10]. The exact cause of the enhanced myofilament $\mathrm{Ca}^{2+}$-sensitivity in cardiac disease models needs to be further investigated and requires analysis of site-specific protein phosphorylation using mass spectrometry as in addition to reduced PKA activity changes in other kinase (protein kinase $\mathrm{C}, \mathrm{CaMKII}$ ) and in phosphatases have been documented in cardiac disease development $[4,5,13,51]$. In a recent study [32], we have observed that alterations in the $\beta$-adrenergic receptor pathway are more pronounced in human IDCM than in ISHD and may reflect sequential changes in cellular protein composition and function and indicates the need to evaluate changes in myofilament properties in the acute phase after the initial disease trigger (e.g., infarction, valve rupture) and at later stages during remodelling of the heart muscle.

The increased myofilament $\mathrm{Ca}^{2+}$-sensitivity reported in end-stage human heart failure is not a consistent observation in different experimental models of heart failure. Similar to humans, an increased myofilament $\mathrm{Ca}^{2+}$-sensitivity has been observed in pig and mice with a myocardial infarction $[10,23]$, while a reduction in $\mathrm{Ca}^{2+}$-sensitivity was found in rat models with congestive heart failure due to pressure overload or myocardial infarction [4, 5]. The direction of the $\mathrm{Ca}^{2+}$-sensitivity shift may involve the stage of cardiac disease (i.e., period after the initial cardiac insult). Possible explanations for the opposite changes in myofilament $\mathrm{Ca}^{2+}$-sensitivity in cardiac disease models have been discussed in recent papers [30, 47, 57].

Apart from reduced PKA-mediated protein phosphorylation other myofilament protein modifications have been reported which may underlie impaired diastolic function of the heart. Varian et al. [70] reported a lack of frequencydependent $\mathrm{Ca}^{2+}$-desensitization in a rabbit model of pressure overload, which was attributed to lack of frequency-dependent cTnI phosphorylation. A reduction in myosin light chain 2 (MLC-2) phosphorylation has been reported in human end-stage heart failure [67], while loss of a transmural MLC-2 phosphorylation gradient has been described in rodent models $[15,21]$. Phosphorylation of MLC-2 has been shown to enhance cross-bridge kinetics and force production per unit $\mathrm{Ca}^{2+}$ [55], while ablation of MLC-2 phosphorylation in mice resulted in a blunted 
response to $\beta$-adrenergic receptor stimulation [54]. Specific and selective proteolysis of cTnI at its $\mathrm{C}$-terminus has been proposed to play a key role in human myocardial ischemic disease, including stunning [27, 52]. The C-terminally truncated cTnI protein has been reported to reduce the force-generating capacity upon ischemia-reperfusion in rodent studies. Incorporation of C-terminal truncated cTnI in rat cardiac muscle depressed maximal force and increased cross-bridge kinetics [60]. However, exchange of C-terminal truncated cTnI in human cardiomyocytes had no effect on maximal force development and increased $\mathrm{Ca}^{2}$
${ }^{+}$-sensitivity of the myofilaments [49]. This indicates that cTnI truncation at the $\mathrm{C}$-terminus in human cardiomyocytes impairs diastolic rather than systolic function. In contrast, truncation of $\mathrm{cTnI}$ at the N-terminus has been shown to enhance ventricular diastolic function $[3,76]$.

Apart from the increased myofilament responsiveness to $\mathrm{Ca}^{2+}$ in end-stage failing human hearts, studies in cardiomyocytes isolated from cardiac catheter biopsies from HFNEF patients revealed significantly elevated passive stiffness compared to control cells (Fig. 3a) [11, 63]. The unique advantage of the catheter biopsies is that in vivo
Fig. 3 a Isolation of single Triton-permeabilized cardiomyocytes from biopsies taken during cardiac catheterization from patients with a diastolic dysfunction evident from increased left ventricular (LV) end-diastolic pressures (>16 mmHg: heart failure patients with normal (or preserved) LV ejection fraction, $H F N E F$ ) revealed increased passive stiffness compared to control cells from patients with normal LV ejection fraction and normal LV end-diastolic pressure [11]. The high passive stiffness was corrected to control values upon treatment with protein kinase A (PKA), suggesting that the high passive force is largely caused by hypophosphorylation of a sarcomeric protein (most likely titin [7]). b A significant relation was found between in vivo LV enddiastolic pressure and cardiomyocyte stiffness, indicating that the in vivo diastolic dysfunction in HFNEF patients is at least partly due to an intrinsic defect of the myofilaments. c Illustrates that the increased myofilament passive stiffness would impair diastolic function of the heart of HFNEF patients compared to controls, while the force-generating capacity of the myofilaments during systole may be somewhat lower compared to controls. d PKA treatment corrected myofilament diastolic dysfunction to values observed in controls
A.

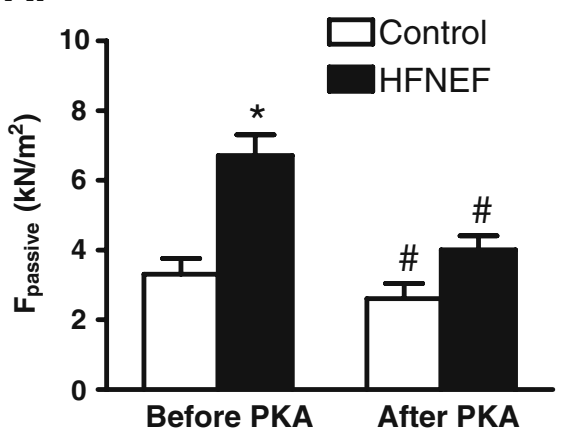

B.

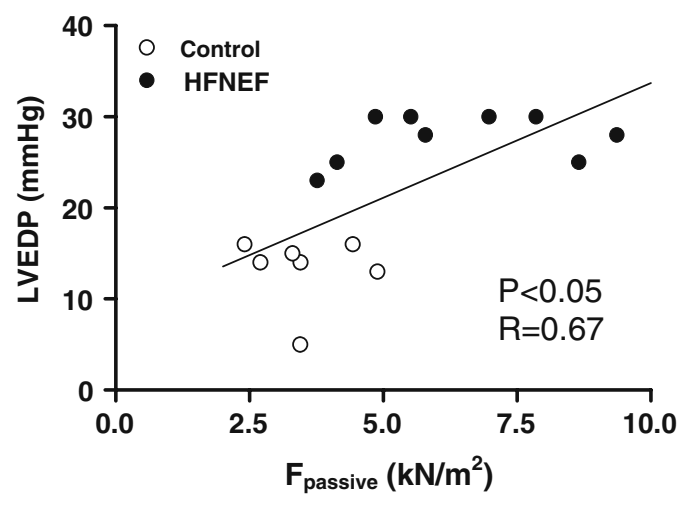

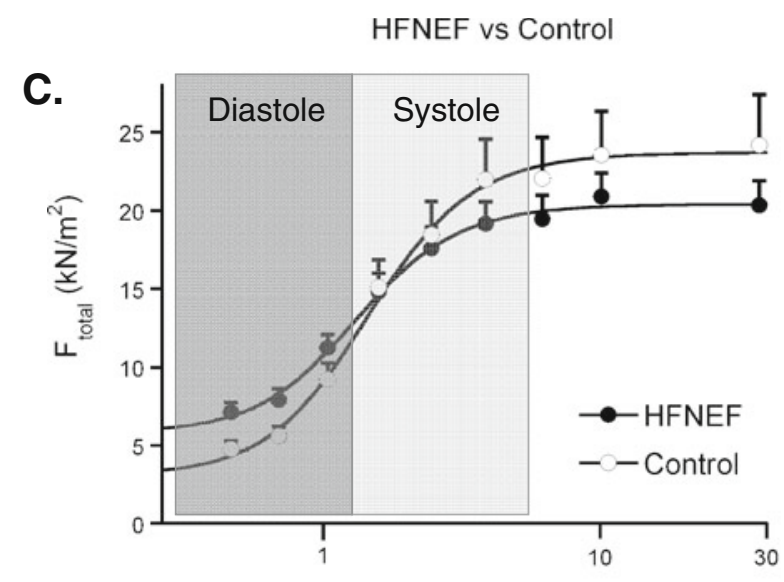

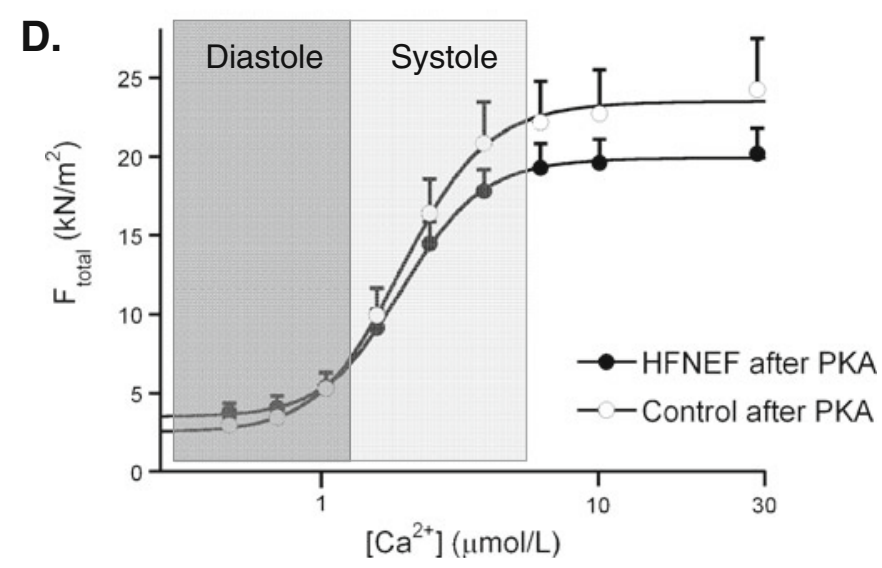




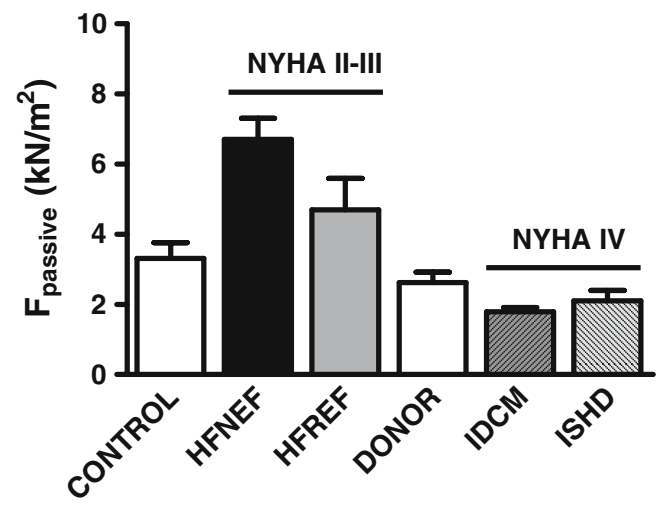

Fig. 4 Comparison of passive force measurements in cells isolated from cardiac biopsies taken during cardiac catheterization (control, $H F N E F$, and HFREF) and from heart tissue obtained during heart transplantation surgery (donor, IDCM, and ISHD) illustrates high passive stiffness in HFNEF and HFREF patients, similar values in control and donor hearts, and low passive force in idiopathic and ischemic end-stage failing cardiomyopathy

hemodynamic data are collected at the time of biopsy procurement and samples are directly frozen in liquid nitrogen, which will fix phosphorylation status of the myofilament proteome. This allowed us to show that the high intrinsic passive stiffness of the myofilaments correlated well with LV end-diastolic pressure (Fig. 3b) [11], which indicates that increased passive myofilament stiffness is an important contributor to diastolic dysfunction in HFNEF patients. Compared to control cells from individuals with normal LVEF and normal LV end-diastolic pressure, force development by the myofilaments was higher at low "diastolic" $\mathrm{Ca}^{2+}$ concentrations and slightly lower at higher "systolic" $\mathrm{Ca}^{2+}$ concentrations in HFNEF as illustrated in the force-calcium relations in Fig. 3c. Treatment with exogenous PKA significantly reduced passive stiffness and abolished the difference in myofilament passive force between HFNEF and control cells (Fig. 3a, d), while force development at systolic $\mathrm{Ca}^{2+}$ concentrations remained somewhat lower in HFNEF compared to the control group.

Correction of passive stiffness in HFNEF with PKA indicated that the myofilament dysfunction is caused by protein hypophosphorylation. As mentioned above, the main protein involved in myofilament stiffness it the giant sarcomeric protein titin. Previous studies have shown that titin is a target of PKA, PKG, and PKC [34, 41, 75]. Phosphorylation by PKA and PKG have been shown to reduce passive stiffness [41,75], while PKC $\alpha$ treatment increased passive stiffness in mouse and pig myocardium [34]. In addition to reduced cTnI and cMyBP-C phosphorylation, end-stage failing human hearts showed a deficit in titin phosphorylation compared to non-failing donor hearts [40]. A study in catheter biopsies from HFNEF and HFREF patients indicated relative hypophosphorylation of the stiff N2B isoform compared to control samples [12]. These data support the hypothesis that hypophosphorylated titin causes increased passive stiffness in cardiac disease. Until present, no evidence for a detrimental effect of PKC-mediated titin phosphorylation has been found in human cardiac samples. Opposite to the expected increase in passive stiffness, PKC treatment of end-stage failing cardiomyocytes slightly reduced passive force [38]. However, the exact modulating role of PKC-mediated titin phosphorylation on passive stiffness in human myocardium should be more carefully assessed in cardiac tissue which is obtained after different stimuli, e.g., after alpha-adrenergic receptor stimulation, which is known to activate downstream PKC.

Phosphorylation deficits of titin may be counterbalanced by adaptations in titin isoform composition possibly aimed to lower passive myofibrillar stiffness [14, 35]. Titin isoform switching has been demonstrated in end-stage failing myocardium: a shift from the stiff $\mathrm{N} 2 \mathrm{~B}$ isoform to the compliant N2BA isoform coincided with lower passive stiffness $[46,50]$ and may rescue diastolic dysfunction. Alternatively, a maladaptive shift towards the stiff N2B

\section{Effect $\beta$-blocker therapy}

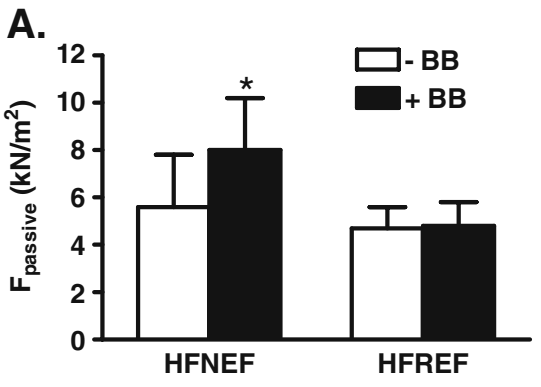

Fig 5 Comparison of heart failure patients with normal $(H F N E F)$ and reduced $(H F R E F)$ left ventricular ejection fraction which received chronic $\beta$-blocker therapy $+\mathrm{BB}$ compared to patients untreated with $\beta$-blockers $-\mathrm{BB}$ showed higher passive stiffness in HFNEF patients
B.

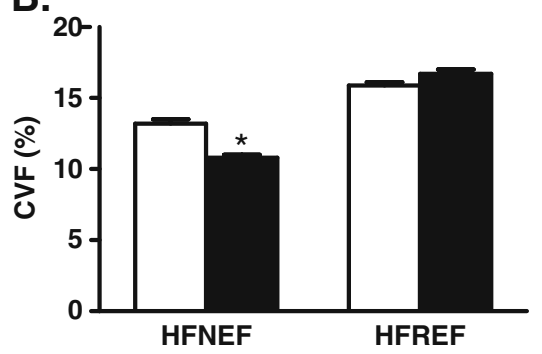

treated with $\beta$-blockers a, while the percentage of collagen volume fraction $(C V F)$ was significantly lower in the HFNEF patients with $\beta$ blockers b. Passive force was higher in HFNEF compared to HFREF patients, while CVF was higher in HFREF than in HFNEF 
isoform has been reported in human samples from patients with aortic stenosis and LV hypertrophy [71], which would exert a detrimental effect on diastolic function.

Figure 4 depicts passive stiffness measured in single cells isolated from catheter biopsies and from hearts which were obtained during heart transplantation surgery. Passive stiffness was highest in HFNEF and HFREF patients which were classified as relatively moderate forms of heart failure (NYHA II to III). Passive stiffness was lowest in end-stage failing human hearts classified as NYHA IV. Noteworthy, passive force development in control cardiac catheter biopsies and donor hearts are similar. The changes in passive stiffness in patient groups compared to the control groups may reflect altered passive stiffness during the progression of cardiac disease, characterized by an enhanced passive stiffness at relatively early stages of the disease where titin phosphorylation deficits are predominant, and lower passive stiffness in end-stage failing hearts in which the shift to more compliant titin balances the perturbations in titin phosphorylation.

\section{Clinical perspectives}

Large clinical trials have convincingly shown that $\beta$ blocker therapy reduces mortality and improves LV function in HFREF patients. In HFNEF patients, favourable effects of $\beta$-blocker therapy on mortality and LV function have not been convincingly demonstrated. Comparison of patients who received $\beta$-blocker therapy and patients untreated with $\beta$-blockers showed higher maximal forcegenerating capacity of myofilament in patients with $\beta$ blocker therapy, which may underlie improved systolic performance [31]. However, $\beta$-blocker therapy increased passive force in HFNEF patients (Fig. 5a), which may even worsen diastolic dysfunction. A positive effect of the $\beta$ blockers was observed on the extracellular matrix as the collagen volume fraction was significantly lower in HFNEF with $\beta$-blockers (Fig. 5b). The opposite effects of $\beta$-blocker therapy on two important determinants of cardiac diastolic function may partly explain the inconsistent results of $\beta$ blocker trials in HFNEF patients. Moreover, although collagen deposition may underlie diastolic dysfunction, within the physiologic sarcomere lengths, stiffness is largely determined by titin. In a recent study, Chung and Granzier [19] have shown that titin is the dominant contributor to LV passive pressure within physiological volumes, while the extracellular matrix exerts a dominant effect on LV pressure at larger volumes. As diastolic dysfunction is present in both HFNEF and HFREF patients and is also a major problem in the growing population of patients with diabetic cardiomyopathy [64], it is of great relevance to design a targeted treatment to titin-mediated passive stiffness. Benefits of therapy targeted at myofilament function may depend on the stage of cardiac disease. In pigs, $\beta$-blocker therapy directly initiated after a myocardial infarction reversed the increased myofilament $\mathrm{Ca}^{2+}$-sensitivity to values observed in sham animals and significantly reduced passive stiffness in infarct animals [24]. The latter observations are in contrast with the data from our human studies, which showed an increase in passive force in $\beta$-blocker treated HFNEF patients (Fig. 5a) and a minor increase in myofilament $\mathrm{Ca}^{2+}$-sensitivity (not shown) [31]. Although there may be species differences, these conflicting data may also be explained by timing at which therapy is initiated. Longitudinal studies in large animal models [45, 74] are warranted to disentangle adaptive from maladaptive myofilament protein changes in the initiation and progression of diastolic dysfunction in heart failure.

Acknowledgment I would like to thank Diederik Kuster for his excellent advice on the design of the figures.

Open Access This article is distributed under the terms of the Creative Commons Attribution Noncommercial License which permits any noncommercial use, distribution, and reproduction in any medium, provided the original author(s) and source are credited.

\section{References}

1. Ahmed A, Zile MR, Rich MW et al (2007) (2007) Hospitalizations due to unstable angina pectoris in diastolic and systolic heart failure. Am J Cardiol 99:460-464

2. Antoons G, Mubagwa K, Nevelsteen I et al (2002) Mechanisms underlying the frequency dependence of contraction and $\left[\mathrm{Ca}^{2+}\right] \mathrm{i}$ transients in mouse ventricular myocytes. J Physiol 543:889-898

3. Barbato JC, Huang QQ, Hossain MM et al (2005) Proteolytic Nterminal truncation of cardiac troponin I enhances ventricular diastolic function. J Biol Chem 280:6602-6609

4. Belin RJ, Sumandea MP, Kobayashi T et al (2006) Left ventricular myofilament dysfunction in rat experimental hypertrophy and congestive heart failure. Am J Physiol Heart Circ Physiol 291: $\mathrm{H} 2344-\mathrm{H} 2353$

5. Belin RJ, Sumandea MP, Allen EJ et al (2007) Augmented protein kinase $\mathrm{C}$ - $\alpha$-induced myofilament protein phosphorylation contributes to myofilament dysfunction in experimental congestive heart failure. Circ Res 101:195-204

6. Bers DM (2002) Cardiac excitation-contraction coupling. Nature 415:198-205, Review

7. Bers DM (2006) Altered cardiac myocyte Ca regulation in heart failure. Physiology (Bethesda) 21(Bers DM):380-387, Review

8. Bhatia RS, Tu JV, Lee DS et al (2006) (2006) Outcome of heart failure with preserved ejection fraction in a population-based study. N Engl J Med 355:260-269

9. Bodor GS, Oakeley AE, Allen PD et al (1997) Troponin I phosphorylation in the normal and failing adult human heart. Circulation 96:1495-1500

10. Boontje NM, Merkus D, Zaremba R et al (2011) Enhanced myofilament responsiveness upon $\beta$-adrenergic stimulation in postinfarct remodeled myocardium. J Mol Cell Cardiol 50:487-499 
11. Borbély A, van der Velden J, Bronzwaer JGF et al (2005) Cardiomyocyte stiffness in diastolic heart failure. Circulation 111:774-781

12. Borbely A, Falcao-Pires I, van Heerebeek L et al (2009) Hypophosphorylation of the stiff N2B titin isoform raises cardiomyocyte resting tension in failing human myocardium. Circ Res 104:780-786

13. Bowling N, Walsh RA, Song G et al (1999) Increased protein kinase $\mathrm{C}$ activity and expression of $\mathrm{Ca}^{2+}$-sensitive isoforms in the failing human heart. Circulation 99:384-391

14. Cazorla O, Freiburg A, Helmes M et al (2000) Differential expression of cardiac titin isoforms and modulation of cellular stiffness. Circ Res 86:59-67

15. Cazorla O, Szilagyi S, Le Guennec JY et al (2005) Transmural stretch-dependent regulation of contractile properties in rat hearts and its alteration after myocardial infarction. FASEB J 19:88-90

16. Cazorla O, Szilagyi S, Vignier N et al (2006) Length and protein kinase A modulations of myocytes in cardiac myosin binding protein C-deficient mice. Cardiovasc Res 69:370-380

17. Chen PP, Patel JR, Rybakova IN et al (2010) Protein kinase Ainduced myofilament desensitization to $\mathrm{Ca}^{2+}$ as a result of phosphorylation of cardiac myosin-binding protein C. J Gen Physiol 136:615-627

18. Chimenti C, Hamdani N, Boontje NM et al (2008) Myofilament dysfunction in human cardiomyocytes with Fabry disease. Am J Pathol 172:1482-1490

19. Chung CS, Granzier HL (2011) Contribution of titin and extracellular matrix to passive pressure and measurement of sarcomere length in the mouse left ventricle. J Mol Cell Cardiol 50:731-739

20. Copeland O, Sadayappan S, Messer AE et al (2010) Analysis of cardiac myosin binding protein-C phosphorylation in human heart muscle. J Mol Cell Cardiol 49:1003-1011

21. Davis JS, Hassanzadeh S, Winitsky S et al (2001) The overall pattern of cardiac contraction depends on a spatial gradient of myosin regulatory light chain phosphorylation. Cell 107:631-641

22. De Clerck NM, Claes VA, Brutsaert DL (1981) Effect of temperature on the mechanical behaviour of single skinned cardiac cells. J Muscle Res Cell Motil 2:183-191

23. De Waard MC, van der Velden J, Bito V et al (2007) Early exercise training normalizes myofilament function and attenuates left ventricular pump dysfunction in mice with a large myocardial infarction. Circ Res 100:1079-1088

24. Duncker DJ, Boontje NM, Merkus D et al (2009) Prevention of myofilament dysfunction by beta-blocker therapy in post-infarct remodeling. Circ Heart Failure 2:233-242

25. El-Armouche A, Pohlmann L, Schlossarek S et al (2007) Increased phosphorylation levels of cardiac myosin-binding protein- $\mathrm{C}$ in human and experimental heart failure. J Mol Cell Cardiol 43:223-229

26. Fabiato A, Fabiato F (1975) Contractions induced by a calciumtriggered release of calcium from the sarcoplasmic reticulum of single skinned cardiac cells. J Physiol 3:469-495

27. Gao WD, Atar D, Liu Y et al (1997) Role of troponin I proteolysis in the pathogenesis of stunned myocardium. Circ Res 80:393-399

28. Gautel M, Zuffardi O, Freiburg A et al (1995) Phosphorylation switches specific for the cardiac isoform of myosin binding protein-C: a modulator of cardiac contraction? EMBO J 14:19521960

29. Hamdani N, Kooij V, Merkus D et al (2008) Sarcomeric dysfunction in heart failure. Cardiovasc Res 77:649-658

30. Hamdani N, de Waard MC, Messer AE, Boontje NM, Kooij V, van Dijk SJ, Versteilen A, Lamberts R, Merkus D, dos Remedios $\mathrm{C}$ et al (2008) Myofilament dysfunction in cardiac disease from mice to men. J Muscle Res Cell Motil 29:189-201
31. Hamdani N, Paulus WJ, van Heerebeek L et al (2009) Distinct myocardial effects of beta-blocker therapy in heart failure with normal and reduced left ventricular ejection fraction. Eur Heart $\mathrm{J}$ 30:1863-1872

32. Hamdani N, Borbely A, Veenstra SPGR et al (2010) Diverse alterations in sarcomeric protein composition and function in ischemic and idiopathic dilated cardiomyopathy. J Muscle Res Cell Motil 31:289-301

33. Hanft LM, Korte FS, McDonald KS (2008) Cardiac function and modulation of sarcomeric function by length. Cardiovasc Res 77:627-636

34. Hidalgo C, Hudson B, Bogomolovas J et al (2009) PKC phosphorylation of titin's PEVK element: a novel and conserved pathway for modulating myocardial stiffness. Circ Res 105:631638

35. Jaber WA, Maniu C, Krysiak J et al (2008) Titin isoforms, extracellular matrix, and global chamber remodeling in experimental dilated cardiomyopathy: functional implications and mechanistic insight. Circ Heart Fail 3:192-199

36. Konhilas JP, Irving TC, de Tombe PP (2002) Frank-Starling law of the heart and the cellular mechanisms of length-dependent activation. Pflugers Arch 445:305-310

37. Kooij V, Saes M, Jaquet K et al (2010) Effect of troponin I Ser23/ 24 phosphorylation on $\mathrm{Ca}^{2+}$-sensitivity in human myocardium depends on the phosphorylation background. J Mol Cell Cardiol 48:954-963

38. Kooij V, Boontje NM, Zaremba R et al (2010) Protein kinase C $\alpha$ and $\varepsilon$ phosphorylation of troponin and myosin binding protein $\mathrm{C}$ reduce $\mathrm{Ca}^{2+}$-sensitivity in human myocardium. Bas Res Cardiol 105:289-300

39. Korte FS, McDonald KS, Harris SP et al (2003) Loaded shortening, power output, and rate of force redevelopment are increased with knockout of cardiac myosin binding protein-C. Circ Res 93:752-758

40. Krüger M, Linke WA (2006) Protein kinase-A phosphorylates titin in human heart muscle and reduces myofibrillar passive tension. $\mathrm{J}$ Muscle Res Cell Motil 27:435-444

41. Krüger M, Kötter S, Grützner A et al (2009) Protein kinase G modulates human myocardial passive stiffness by phosphorylation of the titin springs. Circ Res 104:87-94

42. Lamberts RR, Soekhoe TW, Hamdani NM et al (2007) Frequency-dependent $\mathrm{Ca}^{2+}$-desensitization in failing rat hearts. $\mathrm{J}$ Physiol London 582:695-709

43. Layland J, Kentish JC (1999) Positive force- and $\left[\mathrm{Ca}^{2+}\right] \mathrm{i}$ frequency relationships in rat ventricular trabeculae at physiological frequencies. Am J Physiol Heart Circ Physiol 276:H9H18

44. Lecarpentier Y, Vignier N, Oliviero P et al (2008) Cardiac Myosin-binding protein $\mathrm{C}$ modulates the tuning of the molecular motor in the heart. Biophys J 95:720-728

45. Lewinter MM, Popper J, McNabb M et al (2010) Extensible behavior of titin in the miniswine left ventricle. Circulation 121:768-774

46. Makarenko I, Opitz CA, Leake MC et al (2004) Passive stiffness changes caused by upregulation of compliant titin isoforms in human dilated cardiomyopathy hearts. Circ Res 95:708-716

47. Marston SB, de Tombe PP (2008) Troponin phosphorylation and myofilament $\mathrm{Ca}^{2+}$-sensitivity in heart failure: increased or decreased? J Mol Cell Cardiol 45:603-607

48. Messer AE, Jacques AM, Marston SB (2007) Troponin phosphorylation and regulatory function in human heart muscle: dephosphorylation of Ser23/24 on troponin I could account for the contractile defect in end-stage heart failure. J Mol Cell Cardiol $42: 247-259$

49. Narolska NA, Piroddi N, Belus A et al (2006) Impaired diastolic function after exchange of endogenous troponin I with C-terminal 
truncated troponin I in human cardiac muscle. Circ Res 99:10121020

50. Neagoe C, Kulke M, del Monte F et al (2002) Titin isoform switch in ischemic human heart disease. Circulation 106:1333-1341

51. Neumann J, Eschenhagen T, Jones LR et al (1997) Increased expression of cardiac phosphatases in patients with end-stage heart failure. J Mol Cell Cardiol 29:265-272

52. Murphy AM, Kogler H et al (2000) Transgenic mouse model of stunned myocardium. Science 287:488-491

53. Owan TE, Hodge DO, Herges RM et al (2006) Trends in prevalence and outcome of heart failure with preserved ejection fraction. N Engl J Med 355:251-259

54. Scruggs SB, Hinken AC, Thawornkaiwong A, Robbins J, Walker LA, de Tombe PP et al (2009) Ablation of ventricular myosin regulatory light chain phosphorylation in mice causes cardiac dysfunction in situ and affects neighboring myofilament protein phosphorylation. J Biol Chem 284:5097-5106

55. Scruggs SB, Solaro RJ (2011) The significance of regulatory light chain phosphorylation in cardiac physiology. Arch Biochem Biophys. doi:10.1016/j.abb.2011.02.013

56. Solaro RJ, Moir AJ, Perry SV (1976) Phosphorylation of troponin I and the inotropic effect of adrenaline in the perfused rabbit heart. Nature 262:615-617

57. Solaro RJ, van der Velden J (2010) Why does troponin have so many phosphorylation sites? Fact and fancy. Point-counterpoint. J Mol Cell Cardiol 48:810-816

58. Stelzer JE, Patel JR, Moss RL (2006) Protein kinase A-mediated acceleration of the stretch activation response in murine skinned myocardium is eliminated by ablation of cMyBP-C. Circ Res 99:884-890

59. Stelzer JE, Dunning SB, Moss RL (2006) Ablation of cardiac myosin-binding protein-C accelerates stretch activation in murine skinned myocardium. Circ Res 98:1212-1218

60. Tachampa K, Kobayashi T, Wang H et al (2008) Increased crossbridge cycling kinetics after exchange of $\mathrm{C}$-terminal truncated troponin I in skinned rat cardiac muscle. J Biol Chem 283: 1511415121

61. Tong CW, Gaffin RD, Zawieja DC et al (2004) Roles of phosphorylation of myosin binding protein-C and troponin I in mouse cardiac muscle twitch dynamics. J Physiol 558:927941

62. Van Dijk SJ, Holewijn RA, Tebeest A et al (2009) A piece of the human heart. Variance of protein phosphorylation in left ventricular samples from end-stage primary cardiomyopathy patients. J Muscle Res Cell Motil 30:299-302

63. Van Heerebeek L, Borbély A, Niessen HW et al (2006) Myocardial structure and function differ in systolic and diastolic heart failure. Circulation 113:1966-1973
64. Van Heerebeek L, Hamdani N, Handoko ML et al (2008) Diastolic stiffness of the failing diabetic heart. Importance of fibrosis, advanced glycation end products, and myocyte resting tension. Circulation 117:43-51

65. Van der Velden J, Klein LJ, van der Bijl M et al (1998) Force production in mechanically isolated cardiac myocytes from human ventricular muscle tissue. Cardiovasc Res 38:414-423

66. Van der Velden J, Klein LJ, van der Bijl M et al (1999) Isometric tension development and its calcium sensitivity in skinned myocyte-sized preparations from different regions of the human heart. Cardiovasc Res 42:706-719

67. Van der Velden J, Papp Z, Zaremba R et al (2003) Increased $\mathrm{Ca}^{2+}$ sensitivity of the contractile apparatus in end-stage human heart failure results from altered phosphorylation of contractile proteins. Cardiovasc Res 57:37-47

68. Van der Velden J, Merkus D, Klarenbeek BR et al (2004) Alterations in myofilament function contribute to left ventricular dysfunction in pigs early after myocardial infarction. Circ Res 95: e85-e95

69. Varian KD, Janssen PM (2007) Frequency dependent acceleration of relaxation involves decreased myofilament calcium sensitivity. Am J Physiol Heart Circ Physiol 292:H2212-2219

70. Varian KD, Kijtawornrat A, Gupta SC et al (2009) Impairment of diastolic function by lack of frequency-dependent myofilament desensitization rabbit right ventricular hypertrophy. Circ Heart Fail 2:472-81

71. Williams L, Howell N, Pagano D et al (2009) Titin isoform expression in aortic stenosis. Clin Sci (Lond) 117:237-242

72. Westermann D, Lindner D, Kasner M et al (2011) Cardiac inflammation contributes to changes in the extracellular matrix in patients with heart failure and normal ejection fraction. Circ Heart Fail 1(4):44-52

73. Wolff MR, Buck SH, Stoker SW et al (1996) Myofibrillar calcium sensitivity of isometric tension is increased in human dilated cardiomyopathies. J Clin Invest 98:167-176

74. Wu Y, Bell SP, Trombitas K, Witt CC et al (2002) Changes in titin isoform expression in pacing-induced cardiac failure give rise to increased passive muscle stiffness. Circulation 106:1384-1389

75. Yamasaki R, Wu Y, McNabb M et al (2002) Protein kinase A phosphorylates titin's cardiac-specific N2B domain and reduces passive tension in rat cardiac myocytes. Circ Res 90:1181-1188

76. Yu ZB, Zhang LF, Jin JP (2001) A proteolytic NH2-terminal truncation of cardiac troponin I that is up-regulated in simulated microgravity. J Biol Chem 276:15753-15760

77. Zhang R, Zhao J, Mandveno A et al (1995) Cardiac troponin I phosphorylation increases the rate of cardiac muscle relaxation. Circ Res 76:1028-1035 